\title{
Bir Kadın Sağlığı Sorunu: Genital Mutilasyon
}

\author{
A Female Health Problem: Genital Mutilation
}

\author{
Sevil GÜNAYDIN ${ }^{a}$, Hüsniye DİNÇ ${ }^{b}$
}

\begin{abstract}
ÖZET Dünya Sağlık Örgütü genital mutilasyonu; tıbbi olmayan nedenlerle kadın genital organlarının kısmen veya tamamen çıkarılması, ya da dış genital organlara başka bir biçimde (piercing, kesi yapılması, kazıma, delme veya koterize etme) zarar verilmesi olarak tanımlamıștır. Günümüzde birçok ülkede hala çözümlenememiş önemli bir kadın sağlığı sorunu olan genital mutilasyon, fizyolojik, psikolojik ve cinsel açıdan kadının tüm yaşam evrelerini olumsuz yönde etkilemektedir. Ayrıca prekonsepsiyonel dönemden başlayarak gebelik, doğum ve doğum sonu dönemlerde komplikasyon görülme sıklığını arttırmaktadır. Bu derlemenin amacı kadın genital mutilasyonu konusuna dikkat çekmek, kadın sağlığı üzerine yarattı̆̆ı olumsuz etkilerin farkındalığını arttırmak ve literatür bilgisini paylaşmaktır.
\end{abstract}

Anahtar Kelimeler: Genital mutilasyon, kadın sünneti

\begin{abstract}
The World Health Organization defines genital mutilation as removing part or all of the female genital organ for non-medical purposes; or harming external genital organs in any other way (i.e., piercing, cutting, scraping, pricking or cauterizing). As a significant female health problem which still cannot be resolved in many countries, genital mutilation affects the entire life cycle of women negatively in physiological, psychological, sexual ways. Therefore, beginning from preconceptional period, during pregnancy, birth and postpartum period, it increases the likelihood of complications. The aim of this compilation is to draw attention to the issue of female genital mutilation, to raise awareness about its negative effects on women's health and to share data from the literature about it.
\end{abstract}

Key Words: Female circumcision, genital mutilation

\section{Giriş}

Genital mutilasyon; Dünya Sağlık Örgütü (DSÖ) ve Birleşmiş Milletler (BM) tarafindan "tıbbi olmayan nedenlerden dolayı kadın genital organlarının kısmen veya tamamen çıkarılması" olarak tanımlanmıştır. ${ }^{1}$

Terapötik olmayan nedenlerle yapılan ve tıbben gereksiz olan kadın genital mutilasyon (KGM), son derece ac1 verici ve ciddi sağl1k sonuçlarına neden olan bir problemdir. ${ }^{2}$ KGM kadın ve kızların insan hakları ihlali olarak kabul edilmektedir. Çünkü KGM kadınların ve kız çocuklarının birçok yönden zarar gördüğü, bütüncül açıdan gelişimlerini sınırlayan, toplumsal eşitliğin sağlanmasındaki en büyük engellerden biridir. ${ }^{3}$ Ayrıca kadınlara ve kılara karşı yapılan bir şiddet şekli olan KGM, mevcut çocuk ve yetişkin koruma yapılarının, politika ve prosedürlerin bir parçası olarak ele alınmalıdır. $^{2}$

Birçok toplumda KGM geleneksel bir uygulama olarak kabul edilir ve uygulanır. Kadın sünneti, ailelerin ve toplumun içinde olduğu kültürel, dini ve sosyal faktörlerin bir karışımını içerir. Toplumsal normlara uyum sağlamak ve devam ettirmek için baskı oluşturur. KGM genellikle düzgün bir kız yetiştirmenin gerekli bir parçası, yetişkinlik ve evliliğe hazırlamanın bir yolu olarak kabul edilir. Ayrıca uygun cinsel davranış, evlilik öncesi bekâret ve evlilik sadakati gibi inançlara motive eder. Birçok toplumda kadınlarda cinsel istekte azalmaya yol açtığına ve bu

Geliş Tarihi/Received:25.06.2015/Kabul Tarihi/Accepted: 12.07.2015

a Arş. Gör., İstanbul Üniversitesi Sağlık Bilimleri Fakültesi, Ebelik Bölümü / İstanbul, e-mail: svlgunaydin@ hotmail.com

b Arş. Gör. Dr., İstanbul Üniversitesi Sağlık Bilimleri Fakültesi, Ebelik Bölümü / İstanbul, e-mail: husniyedinc@hotmail.com 
nedenle de kadınların "yasadışı" cinsel eylemler yaşamalarını engellediğine inanılır. Diğer bir inanış ise KGM sonrasında çıkarılan vücut parçaları ile kadınların "temiz" ve "güzel" olduğu inancıdır. Hiçbir dini dayanağı olmamasına rağmen KGM uygulayıcıları bunun dini açıdan desteklendiğine inanırlar. $\mathrm{Bu}$ durum din adamları tarafindan tartışma konusudur. Ancak yerel yapiların gücü ve otoritesi KGM uygulayıcılarını (din adamı, sünnetçi, sağlık personeli vb.) koruma altına alır. ${ }^{4}$

KGM, kadını fiziksel, ruhsal, sosyal ve cinsel yönden tehdit eden çok önemli bir sağlık sorunudur. DSÖ gelişmekte olan ülkelerde mutilasyon uygulanmış göçmen kadın sayısı arttığı için bu ülkelerdeki sağlık profesyonellerine kadın genital mutilasyonu hakkında eğitim verilmesi ve farkındalık kazandırılmasını önermiştir. ${ }^{5}$ Bu derlemenin amacı gelişmekte olan ve son yıllardaki savaşlar nedeniyle fazla sayıda göç alan ülkemizde kadın genital mutilasyonu konusuna dikkat çekmek, kadın sağlığ1 üzerine yarattığ 1 olumsuz etkileri konusunda farkındalık yaratmak ve literatür bilgisini paylaşmaktır.

\section{Kadın Genital Mutilasyonun Tarihçesi ve Yasal Durumu}

Antropologlar genital mutilasyonun başlangıcı hakkında görüş birliğine varamamışlardır. KGM'nin başlangıç tarihinin M.Ö. 15000 yıllarına dayandığ 1 konusunda görüşler olsa da 6000 y1l önce antik Misır'da varolduğu belgelenmiştir. KGM uygulamaları tarihi gelişim sürecinde, hem kadın hem erkek araştırmacılar tarafından yoğun bir şekilde tartışılmıştır. Ülkemizde bu girişimin uygulandığına dair veriler olmamasına rağmen günümüzde birçok ülkede medikal ve paramedikal birçok gerekçe ile azımsanmayacak bir oranda uygulamalar. ${ }^{6}$

Kadın genital mutilasyonu uygulama yaşı ülkeler arasında farklılık göstermektedir. Örneğin, Etiyopya ve Nijerya'da kız bebekleri 8 günlük iken, Misır'da 3-8, Sudan'da 5-8 gün, Somali'de 4-10 yaş, Masai' de evlendikten hemen sonra ve diğer pek çok ülkede ise 13-15 yaşları arasinda uygulamaya maruz kalmaktadırlar. ${ }^{7,8}$

Yasal açıdan ülkelerin bireysel olarak yasalarında düzenleme yapmaları gerekmektedir. Örneğin; Norveç 2004 yılında yasasını KGM'ye yönelik güçlendirerek KGM'nin önlenmesi adına hemşire, ebe, öğretmen ve sosyal yardım sisteminde çalışanlara daha fazla dikkat göstermesi gibi bir görev eklemiştir. Sosyal çalışmac1, hemşire, ebe ve öğretmen dâhil birçok meslek grubuna kızları/kadınları KGM'ye maruz kalmaktan korumaları ve topladıkları verileri mahkemeye veri olarak sunmaları açısından bilgi verilmiştir. ${ }^{9}$

KGM 1990'lı y1llarda uluslararası toplumun gündemine girmiştir. BM, 2002 yılında ülkelere KGM gibi kadın ve kız çocuklarının sağlığını etkileyen geleneksel uygulamaların yasaklanması konusunda tedbirler almaya yönelik çağrıda bulunmuştur. Ardından 2003 yilından itibaren 6 Şubat'ın Uluslararası Kadın Genital Mutilasyonunun Sifir Tolerans Günü olarak anılmasına karar verilmiştir. ${ }^{10}$ Ayrıca KGM Dünya Sağlık Örgütü (World Health Organization-WHO), Birleşmiş Milletler Çocuklara Yardım Fonu (Children's Rights \& Emergency Relief Organization-UNICEF) ve Birleşmiş Milletler Nüfus Fonu (United Nations Population Fund-UNFPA)'nun ortak raporunda tanimlama ve siniflaması yapılarak mücadele kapsamına alınmıştır. ${ }^{6}$

\section{Kadın Genital Mutilasyonun Tipleri} KGM, DSÖ tarafindan dört tipte sınıflandırılmıştır (Resim-1):

- Tip I, kismen veya tamamen klitoris ve/veya sünnet derisi denilen prepisyumun çıkarılması (klitoridektomi)

- Tip II, klitorisin bütünüyle, labia minörlerin kısmen veya tamamen çıkartılması (kalan dokular vajinal açıklı̆̆ı örtemez)

- Tip III, 'infibulasyon' olarak da bilinen dış genitalin önemli kısmı ya 
da tamamının çıkartılması ve vajinal vestibülün posterior komissürde ufak bir açıklı kalacak şekilde kapatılmas1, bir kaplama mühür oluşturulması yoluyla vajinal açıklığın daralması.

- Tip IV, tıbbi olmayan amaçlar için kadın genital bölgesine yapılan diğer tüm zararlı işlemler, örneğin, piercing, genital bölgeye kesi yapılması, kazıma veya koterize etme. $1,6,11$

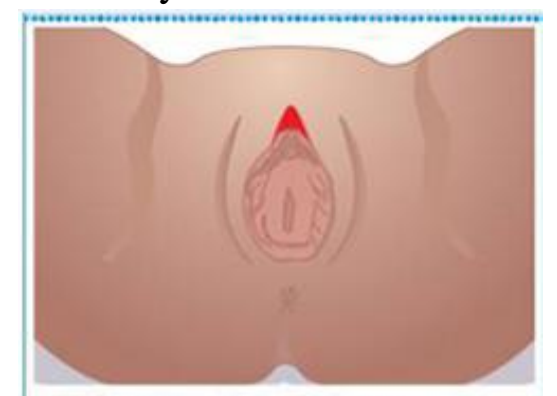

a) Type 1 - clitoridectomy

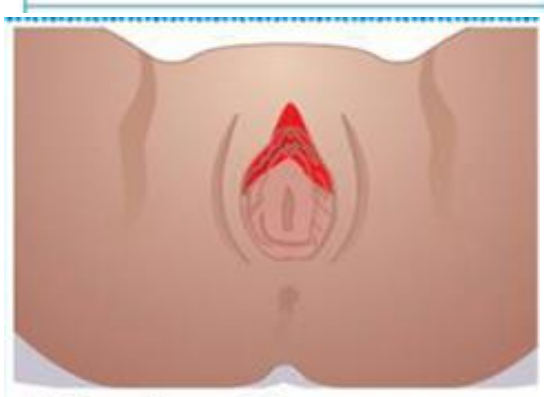

b) Type 2 - excision

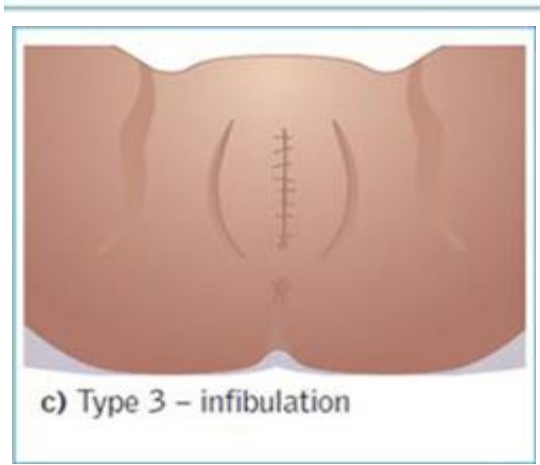

Resim-1: Kadın genital mutilasyonun tipleri $^{12}$

Bütün KGM vakaları arasında \%80 oranında klitoral eksizyon ve labia minörleri kapsayan Tip I ve Tip II görülürken daha ağır şekli olan infibulasyon \%15 oranında görülmektedir. İnfibulasyon sıklığı ve komplikasyonları daha çok Cibuti, Somali ve Sudan'ın kuzey kesimlerinde artış gösterirken Güney Misır, Eritre, Etiyopya, Kuzey Kenya, Mali ve Nijerya'da da yapıldı̆̆ 1 bildirilmiştir. ${ }^{13}$

\section{Kadın Genital Mutilasyonun Prevalansı}

KGM; Afrika, Ortadoğu ve Asya'nın bazı ülkeleri dâhil toplam 28 ülkede ve birçok toplumda köklü bir gelenek olarak uygulanmaktadır. $^{1}$ Orta ve Güney Amerika'daki bazı etnik gruplar arasında ise KGM'nin bazı formlarını görmek mümkündür. ${ }^{14}$ Bugün dünyada $\mathrm{KGM}$ uygulamasına maruz kalmış tahminen 130140 milyon kız ve kadın bulunmakta ve her yıl 3 milyon kız bu uygulamanın tehdidi altında yaşamaktadır. ${ }^{1}$ KGM prevalansı geniş katılımlı çalışmalarda \%38-63 gibi yüksek oranlarda belirlenmiştir. ${ }^{6}$ Tablo-1'de bazı ülkelerdeki KGM tiplerine ve prevalanslarına yer verilmiştir.

\section{Kadın Genital Mutilasyon ve Kadın Sağlı̆̆ı}

KGM; kızlar ya da kadınlar için sağlığı riske sokacak bir davranıştır. ${ }^{16,17} \mathrm{Bu}$ geleneksel uygulama genellikle makas, jilet ve/veya kırık cam kullanarak anestezi olmadan yapılır. Risklerin ve gelişebilecek komplikasyonların sonuçları ciddi ve yaşamı tehdit edici olabilir. ${ }^{16}$

\section{Kadın Sağlığı Açısından Gelişebilecek Komplikasyonlar}

KGM' nin çok sayıda komplikasyonu rapor edilmesine rağmen uzun dönem sonuçları hakkında yapılan sistematik çalışmalar bulunmamaktadır. ${ }^{13}$ Tablo-2 ve Tablo-3'de KGM' nin kisa ve uzun dönem komplikasyonlarına yer verilmiştir.

KGM, özellikle kırsal kesimde, son derece olumsuz koşullarda sağlık personeli dışındaki uygulamacılar tarafından uygulanmakta ve erken dönemde şiddeti ağır hemoraji, bunlarla ilişkili şok ve ölüm gibi ciddi sorunlara, geç dönemde ise kronik genital ve/veya üriner enfeksiyonlar, keloid oluşumu, fertilite veya doğurma problemleri 
Tablo-1: Bazı ülkelere göre KGM prevalansı ve tipleri ${ }^{15}$

\begin{tabular}{lll}
\hline Ülke & $\begin{array}{l}\text { Prevalans } \\
(\boldsymbol{\%})\end{array}$ & KGM Tip \\
\hline Burkina Faso & 72 & Tip II \\
\hline $\begin{array}{l}\text { Orta Afrika } \\
\text { Cumhuriyeti }\end{array}$ & 43 & Tip I ve II \\
\hline Fildişi Sahili & 43 & Tip I \\
\hline Mısır & 97 & Tip I (\%17), Tip II (\%72), Tip III (\%9) \\
\hline Eritre & 95 & Tip I (\%64), Tip II (\%4), Tip III (\%34) \\
\hline Gine & 99 & Tip II \\
\hline Kenya & 38 & Tip I ve II, Tip III doğu bölgelerde uygulanır \\
\hline Mali & 94 & Tip I (\%52) Tip II (\%47), Tip III Güney Mali (\%1) \\
\hline Niger & 5 & Tip II \\
\hline Nigerya & 25 & Tip I, Tip II güney bölgede baskin, Tip III sadece \\
\hline Somali & $98-100$ & Tip III \\
\hline Sudan & 89 & Tip I (\%15), Tip II (\%3), Tip III (\%82) \\
\hline Tanzanya & 18 & Tip I ve II \\
\hline Togo & 12 & Tip II \\
\hline Yemen & 23 & Veri yok \\
\hline
\end{tabular}

gibi birçok kalıcı ve tedavisi zor sağlık sorunlarına neden olmaktadır. ${ }^{6}$

Alsibiani ve Rouzi'nin (2010) yapmış olduğu prospektif vaka kontrol çalışmasında KGM'nin cinsel fonksiyona etkisi araştırılmıştır. Kadın Cinsel İşlev Ölçeği (FSFI) kullanılarak yapılan çalışmada demografik özellikleri benzer olan 130 KGM yapılan kadın ile 130 KGM yapılmayan kadın karşılaştırılmıştır. İki grup arasında cinsel istek ve ağrı skorları açısından fark bulunmazken, uyarılma, lubrikasyon, orgazm ve doyum arasinda istatistiksel olarak anlamlı fark saptanmıştır. Çalışma sonuçlarına göre KGM kadınların cinsel fonksiyonunu olumsuz yönde etkilemektedir. ${ }^{11}$ Cinsel fonksiyonda değişikliklere neden olan KGM kadınları şiddete maruz kalma açısından da etkilemektedir. KGM yapılan kadınların partner şiddetinin değişik türlerine (fiziksel, cinsel ve duygusal) diğer kadınlara nazaran yaklaşık 9 kat daha fazla maruz kaldıklarını gösteren çalışmalar bulunmaktadır. ${ }^{18}$

KGM'li kadınlarda seksüel fonksiyonların düzeltilmesi için psikoterapi ve medikal tedaviler yapılabilmektedir.
Bunların yanı sıra, koitusa olanak sağlamak ve koitus sirasindaki tekrarlayan travmaların önüne geçmek, ağrıyı gidermek ve seksüel olarak uyarılabilir kalan dokuları (vestibüler bulbus, klitoral artık vs.) ortaya çıkarmak için cerrahi müdahale gerekliliği de bildirilmiştir. $\mathrm{Bu}$ amaçla olgudan olguya değişen farklı cerrahi uygulamalar yapılmaktadır. Genel adi ile 'deinfibulasyon' denen ve diş genital yapılar1 normal anatomik lokalizasyonlarına döndürmeyi amaçlayan bir cerrahi tedavi uygulanmakta, gerektiği ve şartların uygun olduğu durumlarda çeşitli 'klitorolabioplasti' yöntemleri ile kombine edilmektedir. ${ }^{6}$ 
Tablo-2: Kadın genital mutilasyonun kısa dönem komplikasyonları

\begin{tabular}{l}
\hline Komplikasyonlar \\
\hline$\checkmark$ Kanama \\
\hline$\checkmark$ Ağr1 \\
\hline$\checkmark$ Şok \\
\hline$\checkmark$ Enfeksiyon (tetanoz, sepsis, kan \\
yoluyla bulaşan enfeksiyonlar (HIV, \\
Hepatit B, C gibi)) \\
$\checkmark \checkmark$ İdrar retansiyonu ${ }^{2,13-15,19,20}$ \\
\hline$\checkmark$ Bitişik dokularda hasar ${ }^{2,13,20}$ \\
\hline$\checkmark$ Organ hasarr, \\
\hline$\checkmark$ Ölüm \\
\hline
\end{tabular}

Tablo-3: Kadın genital mutilasyonun uzun dönem komplikasyonları

\begin{tabular}{|c|}
\hline Komplikasyonlar \\
\hline$\checkmark$ Yara izi ve skar oluşumu \\
\hline$\checkmark$ Kronik pelvik enfeksiyon \\
\hline$\checkmark$ İnfertilite \\
\hline $\begin{array}{l}\checkmark \text { Psikolojik etkiler (cinsel istekte } \\
\text { azalma, anksiyete, depresyon vb.) }\end{array}$ \\
\hline$\checkmark$ Hematokolpos \\
\hline $\begin{array}{l}\checkmark \text { Vulvada epidermoid kist, skar veya } \\
\text { keloid oluşumu }\end{array}$ \\
\hline $\begin{array}{l}\checkmark \text { Menstruasyon güçlükleri (dismenore } \\
\text { vb.) }\end{array}$ \\
\hline $\begin{array}{l}\checkmark \text { Tekrarlayan idrar yolu } \\
\text { enfeksiyonu }^{2,13-15,19,20}\end{array}$ \\
\hline$\checkmark$ Böbrek hasarı \\
\hline$\checkmark$ Üriner ve fekal inkontinans \\
\hline$\checkmark$ Cinsel disfonksiyon \\
\hline $\begin{array}{l}\checkmark \text { HIV ve diğer cinsel yolla bulaşan } \\
\text { hastalıklar, }{ }^{2,13,20}\end{array}$ \\
\hline $\begin{array}{l}\checkmark \text { Gebelik, doğum ve yenidoğan } \\
\text { komplikasyonlar1 }\end{array}$ \\
\hline$\checkmark$ Anormal servikal sitoloji ${ }^{15}$ \\
\hline$\checkmark$ Yürürken veya otururken ağr1 ${ }^{20}$ \\
\hline
\end{tabular}

Kadın Genital Mutilasyonun Cinsel Sağlığa ve Kadın Psikolojisine Etkileri

KGM'li çoğu kadının evlilikte ortaya çıkan cinsel ilişki ile ilgili sorunları vardır. Çünkü KGM nedeniyle genital bölge ağrılı ve travmalıdır. ${ }^{13-15,19}$ KGM cinselliği çoğu zaman azaltır ya da yok eder. Eğer klitoris yok edilmişse, klitoral orgazm imkânsızdır. ${ }^{15,19}$ KGM sonucu oluşan skar dokusunun fazla olması sebebiyle vajinal darlık, cinsel ilişkide zorlanma görülebilir. ${ }^{13}$ Oluşan skar dokusunda cinsel ilişkide zorlama sonucu perineal yırtıklar ve kanama görülebilir, ilerleyen zamanlarda ise vajinismus ve disparoniye sebep olabilir. ${ }^{13-15,19}$ Vaginal ilișki sağlanamayan durumlarda sürekli anal ilişkinin olması ${ }^{13,19}$ anal fistül ve fekal inkontinansa sebep olabilir. ${ }^{19}$ Ayrıca eşlerin isteği ile kadına defibulasyon (düzeltme) yapılarak cinsel ilişkide iyilik halinin artırılabileceğ $i$ vurgulanmaktadır. $^{7}$

KGM'li kadınların benlik saygısının düşük olduğu ve bu kadınlar arasında cinselliği hissetmenin kötü bir şey olduğu fikrinin yaygın olduğu belirlenmiştir. ${ }^{19}$ Ayrıca psikolojik açıdan genital fobi, anksiyete, depresyon, nöroz, psikoz yaşama durumu ve intihar girişimi fazladır. ${ }^{13,19}$

\section{Kadın Genital Mutilasyonu ve Gebelikten Korunma Yöntemleri}

DSÖ kadın genital mutilasyonu olmuş kadinlara mutilasyon tiplerine uygun gebelikten koruyucu yöntemler önermektedir. $\mathrm{Bu}$ kadınlara yöntem önerirken; çok iyi bir genital değerlendirme yapılarak genital mutilasyon tipinin doğru belirlenmesi ve kadınlarda enfeksiyon varlığının saptanması çok önem taşımaktadır. ${ }^{7}$ KGM uygulanan kadınlarda tiplerine göre kullanılabilecek aile planlaması yöntemleri Tablo 4'te belirtilmiştir. 
Tablo-4: KGM tiplerine göre aile planlaması yöntemleri ${ }^{5}$

\begin{tabular}{|c|c|c|c|c|}
\hline $\begin{array}{l}\text { Kontraseptif } \\
\text { Yöntem }\end{array}$ & $\begin{array}{l}\text { Tip I } \\
\text { (Klitoridektomi) }\end{array}$ & $\begin{array}{l}\text { Tip II } \\
\text { (Eksizyon) }\end{array}$ & $\begin{array}{l}\text { Tip III } \\
\text { (Infibulasyon) }\end{array}$ & Tip IV \\
\hline $\begin{array}{l}\text { Oral } \\
\text { Kontrasepsivon }\end{array}$ & Kullanılabilir & Kullanilabilir & Kullanılabilir & Kullanılabilir \\
\hline Enjeksiyon & Kullanılabilir & Kullanılabilir & Kullanılabilir & Kullanılabilir \\
\hline $\begin{array}{l}\text { Rahim İçi Araç } \\
\text { (RİA) }\end{array}$ & $\begin{array}{l}\text { Kullanılabilir } \\
\text { ancak önce } \\
\text { enfeksiyon } \\
\text { varlığı } \\
\text { dışlanmalıdır }\end{array}$ & $\begin{array}{l}\text { Kullanılabilir } \\
\text { ancak } \\
\text { introtustaki } \\
\text { skar doku RİA } \\
\text { uygulamasını } \\
\text { zorlaştırabilir. } \\
\text { Ayrıca } \\
\text { enfeksiyon } \\
\text { varlığ } 1 \\
\text { dışlanmalıdır }\end{array}$ & $\begin{array}{l}\text { Kullanılamaz, } \\
\text { introitus çok } \\
\text { dardır. Eğer } \\
\text { tercih } \\
\text { edilecekse } \\
\text { defibulasyon } \\
\text { işlemi } \\
\text { yapılmalıdır }\end{array}$ & $\begin{array}{l}\text { Kullanılabilir } \\
\text { ancak öncelikle } \\
\text { labialarda } \\
\text { meydana gelen } \\
\text { uzamış } \\
\text { dokuların } \\
\text { alınması } \\
\text { gerekir. } \\
\text { Enfeksiyon } \\
\text { riski vardır }\end{array}$ \\
\hline $\begin{array}{l}\text { Bariyer Yöntem } \\
\text { (Diyafram, } \\
\text { Spermisit, Kadın } \\
\text { Kondomu, } \\
\text { Servikal kap) }\end{array}$ & Kullanılabilir & Kullanılabilir & $\begin{array}{l}\text { Kullanılabilir } \\
\text { ancak açılık } \\
\text { dar olduğundan } \\
\text { tercih } \\
\text { edilecekse } \\
\text { defibulasyon } \\
\text { işlemi } \\
\text { yapılmalıdır }\end{array}$ & Kullanılabilir \\
\hline Norplant/implant & Kullanılabilir & Kullanılabilir & Kullanılabilir & Kullanılabilir \\
\hline \multicolumn{5}{|l|}{$\begin{array}{l}\text { Doğal } \\
\text { Yöntemler: }\end{array}$} \\
\hline $\begin{array}{l}\text { Isı kontrol } \\
\text { Yöntemi }\end{array}$ & $\begin{array}{l}\text { Danışmanlık } \\
\text { verilerek } \\
\text { kullanılabilir }\end{array}$ & $\begin{array}{l}\text { Danışmanlık } \\
\text { verilerek } \\
\text { kullanılabilir }\end{array}$ & $\begin{array}{l}\text { Danışmanlık } \\
\text { verilerek } \\
\text { kullanılabilir }\end{array}$ & $\begin{array}{l}\text { Danışmanlık } \\
\text { verilerek } \\
\text { kullanılabilir }\end{array}$ \\
\hline $\begin{array}{l}\text { Bazal Vücut Isısı } \\
\text { Yöntemi }\end{array}$ & $\begin{array}{l}\text { Danışmanlık } \\
\text { verilerek } \\
\text { kullanılabilir }\end{array}$ & $\begin{array}{l}\text { Danışmanlık } \\
\text { verilerek } \\
\text { kullanılabilir }\end{array}$ & $\begin{array}{l}\text { Danışmanlık } \\
\text { verilerek } \\
\text { kullanılabilir }\end{array}$ & $\begin{array}{l}\text { Danışmanlık } \\
\text { verilerek } \\
\text { kullanılabilir }\end{array}$ \\
\hline Takvim Yöntemi & $\begin{array}{l}\text { Danışmanlık } \\
\text { verilerek } \\
\text { kullanılabilir }\end{array}$ & $\begin{array}{l}\text { Danışmanlık } \\
\text { verilerek } \\
\text { kullanılabilir }\end{array}$ & $\begin{array}{l}\text { Danışmanlık } \\
\text { verilerek } \\
\text { kullanılabilir }\end{array}$ & $\begin{array}{l}\text { Danışmanlik } \\
\text { verilerek } \\
\text { kullanılabilir }\end{array}$ \\
\hline $\begin{array}{l}\text { Servikal Mukus } \\
\text { Yöntemi }\end{array}$ & $\begin{array}{l}\text { Danışmanlık } \\
\text { verilerek } \\
\text { kullanılabilir } \\
\text { ancak enfeksiyon } \\
\text { dışlanmalıdır }\end{array}$ & $\begin{array}{l}\text { Danışmanlık } \\
\text { verilerek } \\
\text { kullanılabilir } \\
\text { ancak } \\
\text { enfeksiyon } \\
\text { dışlanmalıdır }\end{array}$ & $\begin{array}{l}\text { Kullanılamaz } \\
\text { çünkü } \\
\text { infibulasyon } \\
\text { nedeni ile } \\
\text { servikal mukus } \\
\text { örneği almak ve } \\
\text { testi yapmak } \\
\text { zordur }\end{array}$ & $\begin{array}{l}\text { Danışmanlık } \\
\text { verilerek } \\
\text { kullanılabilir } \\
\text { ancak } \\
\text { enfeksiyon } \\
\text { dışlanmalıdır }\end{array}$ \\
\hline $\begin{array}{l}\text { Laktasyon } \\
\text { Amenoresi }\end{array}$ & $\begin{array}{l}\text { Danışmanlık } \\
\text { verilerek } \\
\text { kullanılabilir }\end{array}$ & $\begin{array}{l}\text { Danışmanlık } \\
\text { verilerek } \\
\text { kullanılabilir }\end{array}$ & $\begin{array}{l}\text { Danışmanlık } \\
\text { verilerek } \\
\text { kullanılabilir }\end{array}$ & $\begin{array}{l}\text { Danışmanlık } \\
\text { verilerek } \\
\text { kullanılabilir }\end{array}$ \\
\hline
\end{tabular}


Kadın Genital Mutilasyonu ve Gebelik Jinekolojik ve obstetrik sorunları değerlendirmeye yarayan pelvik muayene pek çok kadında korku ve tedirginlik yaratır. KGM'liler de ise diğer kadınlara oranla genital sistem anatomisi bozulduğu için bimanuel muayene veya transvajinal görüntüleme yapılması zordur. Ayrıca vajinal darlık sebebiyle gebelik kolay gerçekleşmeyebilir. Pelvik muayenenin yapılamaması birçok riski beraberinde getirir. $^{13,19}$

Literatürde, genital mutilasyon olmuş bazı gebe kadınların; anne karnındaki bebeğin düşük kilolu olmasının doğum kanalından daha rahat ilerleyebileceği düşüncesiyle gebeliklerinde diyet yaptıkları da belirtilmektedir. ${ }^{7}$

KGM'li kadınlarda gebelik sırasında ortaya çıkan bazı fizyolojik değişiklikler nedeniyle komplikasyonlar daha fazla görülür. Gebelikle birlikte tüm genital organlarda kan akımı ve damarlaşma artar. Genital organ dokuları daha fazla enfeksiyona duyarlı hale gelir. Kanda östrojen ve progesteron seviyelerinin artış1 düz kaslar üzerinde gevşetici etki yaratır ve bu da idrar yolu enfeksiyonu olasılığını artırır. ${ }^{13}$

KGM'de epiltel dokudaki değişiklikler sonucunda epidermoid kistler gelişebilir. Gebelik sırasında artan damarlaşma nedeniyle kistin boyutunda artış görülür ve bu kistler portakal büyüklüğüne ulaşabilir. Gebelik sirasında kistin cerrahi yöntemle çıkarılması ciddi kanamalara neden olacağından geçerli bir yöntem değildir. Ameliyat sırasında klitoral arter ve üretra yaralanmalarını önlemek için kist eksize edilirken dikkatli olunmalıdır. Kist basit ve iyi huylu ise doğuma engel olmaz. $\mathrm{Bu}$ konuda sağlık profesyonelleri gebe ve ailesini bilgilendirmeli ve danışmanlık hizmeti sunmalıdır. ${ }^{13}$

Yara yeri enfeksiyonu gelişmiş ise skar dokusunun sertleşmesi ile keloid oluşur. Keloid ise ilk ilişki sırasında veya doğumda sorunlara yol açabilir. Gebelik sırasında çevre dokulardaki damarlaşmanın artmasına bağlı olarak perineal bölgeye cerrahi girişim uygulanmamalidir. Ayrica toplum tarafından keloid dokunun eksizyonu için kullanılan geleneksel yöntemler kanama ve enfeksiyona neden olabilir. Sağllk profesyonelleri gelişebilecek riskler konusunda topluma danışmanlık hizmeti vermelidirler. ${ }^{13}$

\section{Kadın Genital Mutilasyonu Doğum ve Doğum Sonu Dönem}

KGM'li kadınlar doğum sirasında bir dizi komplikasyonla karşılaşırlar. KGM'nin daha şiddetli olduğu tiplerinde ciddi komplikasyonlar görülür. Dolayısıyla infibulasyonlu kadın, doğum eylemi sürecinde yüksek risk taşımaktadır. ${ }^{13} \mathrm{Bu}$ da doğum korkusuna sebep olmaktadır. ${ }^{15}$ İnfibulasyonlu kadınlarda introitus darlık sebebiyle vajinal muayene zor veya mümkün olmadığından doğum eyleminin yönetimi de oldukça zordur. ${ }^{13,15,19}$ KGM'li kadınlarda normal vajinal doğum sirasında epizyotomi gerektiğinden doğumun sezaryenle gerçekleşmesi tercih edilir. ${ }^{15}$

Sezaryen doğum tercih edildiğinde ise dar introitus sebebiyle mesane kateterinin yerleştirilmesi zordur. ${ }^{13,15}$ Ayrıca sezaryen sonrası loşia vajinada birikebilir ve bu da enfeksiyona, puerperal sepsise neden olabilir. ${ }^{19}$

Normal vajinal doğumda ise rijit perine, uzamış ve ilerlemeyen eylemlere sebep olurken eylemin ikinci evresinde ise perineal yırtıklara, kanamaya, fistül oluşumuna, uterus rüptürüne, uterin prolapsuslara, fetal veya maternal ölümlere yol açabilir. ${ }^{13,19,20}$

KGM'li kadınlarda doğum sonu kanama görülme olasılığı fazladır. ${ }^{15} \mathrm{Bu}$ yüzden hemoglobin değerleri hastaneden taburcu olmadan önce kontrol edilmeli, anemi gelişmişse tedavi edilmelidir. Ayrıca kullanılan malzemelerin steril olmayışı, yara yerinin gaita veya idrarla temas etmesi doğum sonu enfeksiyona sebep olabilir. ${ }^{13}$ Ağır vajinal laserasyon gelişen olgularda hastanede kalış süresinde artış görülebilmektedir. $\mathrm{Bu}$ durum nazokomiyal enfeksiyon riskini arttırmaktadır. ${ }^{15}$ Ayrıca gebelikte diyet yapılmasına bağlı olarak 
düşük doğum ağırlıklı bebek doğurma, yenidoğan bebeği canlandırılmak için daha çok resüsitasyon gereksinimi duyulması mutilasyonun doğuma ilişkin komplikasyonları arasında sayılır. ${ }^{7}$

Sonuç olarak; kadın genital mutilasyonu birçok toplumda geleneksel olarak uygulanan ve uluslararası toplumun gündeminde yer bulan önemli bir kadın sağlığı sorunudur. Ülkelere göre farklı uygulama tipleri ve prevalansları bulunan kadın genital mutilasyonu kadın yaşamını tehdit etmekte ve ciddi komplikasyonlara neden olmaktadır.

$\mathrm{Bu}$ doğrultuda önerilerimiz, kadın sağlığının yükseltilmesi ve toplum refahının arttırılması açısından kadın genital mutilasyonu hakkında sağlık profesyonellerinin farkındalığın arttırılması ve bilgi eksikliklerinin giderilmesidir.

\section{Kaynaklar}

1. World Health Organization. An update on WHO's work on female genital mutilation (FGM): Progress report 2011. Available from:

http://whqlibdoc.who.int/hq/2011/WHO RHR_11.18_eng.pdf?ua=1

2. Government HM. Multi-agency practice guidelines: female genital mutilation 2011. Available from: www.dhsspsni.gov.uk/fmg.pdf

3. UNICEF. Legislative reform to support the abandonment of female genital mutilation/cutting 2010. Available from: http://www.unicef.org/policyanalysis/file s/UNICEF LRI Legislative Reform to _support the Abandonment_of_FGMC August 2010.pdf

4. International day of zero tolerance to female genital mutilation. Available from: http://www.un.org/en/events/femalegenit almutilationday/background.shtml

5. Female Genital Mutilation. A Students Manual. Integrating the prevention and management of the health complications into the curcicula of nursing and midwifery ,Geneva, WHO 2001. p.1-104. Available from:
https://www.who.Int/Gender/Other

Health/Studentsmanual/pdf

6. Yeni E. Kadında sirkumsizyon ve genital mutilasyon. Androloji Bülteni 2004;18: 261-264.

7. Aktaş S, Çalık KY. Kadın genital mutilasyonu. Sürekli Tıp Eğitim Dergisi 2010; 19(1): 29-37.

8. Khaled MA, Cox C. Female genital mutilation. Trauma 2000; 2(2):161-167.

9. Lien IL, Schultz JH. Interpreting signs of female genital mutilation within a risky legal framework. International Journal Of Law, Policy And The Family 2014; ebu002.

10. Female Genital Mutilation/Cutting: A statistical overview and exploration of the dynamics of change. Available from: http://www.childinfo.org/files/FGCM L o_res.pdf

11. Alsibiani SA, Rouzi AA. Sexual function in women with female genital mutilation. Fertility And Sterility 2010;93(3):722724.

12. Female genital mutilation (FGM) explained. Available from: http://www.thepoliticaldomain.eu/fgmfemale-genital-mutilation-explained/

13. Rushwan H. Female genital mutilation FGM/ management during pregnancy, childbirth and the postpartum period. International Journal of Gynecology \& Obstetrics 2000;70:99-104.

14. World Health Organization. Library cataloguing-in-publication data. eliminating female genital mutilation: an interagency statement UNAIDS, UNDP, UNECA, UNESCO, UNFPA, UNHCHR, UNHCR, UNICEF, UNIFEM, WHO 2008.

Available from:http://www.un.org/womenwatch/da w/csw/csw52/statements_missions/Intera gency_Statement_on_Eliminating_FGM. pdf

15. Royal College of Obstetricians and Gynaecologists (RCOG). Green-top guideline no. 53 Female genital mutilation and its management 2009. Available from: https://www.rcog.org.uk/guidelines 
16. Perron L, Senikas V. Female genital cutting/mutilation. $J$ Obstet Gynaecol Can 2012;34(2):197-200.

17. Yasin BA, Al-Tawil NG, Shabila NP, AlHadithi TS. Female genital mutilation among Iraqi Kurdish women: a crosssectional study from Erbil city. $B M C$ Public Health 2013;13(809):1-8, doi:10.1186/1471-2458-13-809

18. Salihu HM, August EM, Salemi JL, Weldeselasse H, Sarro YS, Alio AP. The association between female genital mutilation and intimate partner violence. BJOG: An International Journal of Obstetrics \& Gynaecology 2012;119(13):1597-1605.

19. Rymer J. Female genital mutilation. Current Obstetrics \& Gynaecology. 2003;13:185-190.

20. Reyners M. Health consequences of female genital mutilation. Reviews in Gynaecological Practice 2004;4:242251. 